\title{
A CHANGE IN EPIDEMIOLOGY OF JAPANESE ENCEPHALITIS IN BANKURA AND PURULIA DISTRICTS OF WEST BENGAL
}

\author{
Debalina Das ${ }^{1}$,Rehena Sarkar2, Jayanta Bikash Dey33, Syamal Kundu4, Koushik Ghosh ${ }^{5}$ \\ ${ }_{1}^{1}$ Postgraduate Trainee, Department of Microbiology, Bankura Sammilani Medical College, Bankura. \\ ${ }^{2}$ Postgraduate Trainee, Department of Microbiology, Bankura Sammilani Medical College, Bankura. \\ 3 Professor and HOD, Department of Microbiology, Bankura Sammilani Medical College, Bankura. \\ 4 Professor and HOD, Department of General Medicine, Bankura Sammilani Medical College, Bankura. \\ ${ }^{5}$ Demonstrator, Department of Physiology, Calcutta National Medical College, Kolkata.
}

\section{ABSTRACT}

Japanese encephalitis (JE) is a leading cause of encephalitis in India including West Bengal. There is continued occurrence of sporadic cases and small outbreaks in Bankura and Purulia districts of West Bengal. Recent published data regarding the incidence of JE in this part of West Bengal is not available. We analysed the Japanese B encephalitis (JE) seropositive cases from various rural, urban and semiurban areas of the said districts.

\section{AIM OF STUDY}

To study the epidemiology of Japanese encephalitis in Bankura and Purulia district of West Bengal for the year 2014.

\section{MATERIALS AND METHODS}

The study was done between January 2014 to December 2014. CSF and serum samples were collected from patients admitted with acute encephalitis syndrome from Paediatric and Medicine wards. The collected samples were analysed for JE specific IgM antibody by IgM antibody capture enzyme linked immunosorbent assay (MAC-ELISA) using kits from NIV (Pune).

\section{RESULTS}

During the study period, samples from 287 suspected patients were tested for JE out of which $29(10 \%)$ were positive for IgM antibodies of which $16(55 \%)$ were male and 13 (45\%) were female. Of the 29 reactive cases, $13(45 \%)$ were paediatric cases (<12 years) and 16 (55\%) were adults. The number of seropositive cases referred from Bankura and Purulia were 13 (45\%) and 16 (55\%) respectively. The percentage of IgM positive JE was found to be high during the months of September and October. No death was reported in last year due to JE but $30 \%$ patients were discharged with sequelae.

\section{CONCLUSION}

Unlike other studies, the number of seropositive JE was more in adult population than paediatric population. It may be due to vaccination in 1-15 years age group. The continued occurrence of sporadic cases and small outbreaks during the monsoons can be due to the increased vector burden in the paddy fields in this region of West Bengal. No death was reported which indicates an improvement in the management of JE cases over time.

\section{KEYWORDS}

Japanese Encephalitis, Flavivirus, IgM MAC ELISA.

HOW TO CITE THIS ARTICLE: Das D, Sarkar R, Dey JB, et al. A change in epidemiology of Japanese encephalitis in Bankura and Purulia districts of West Bengal. J. Evolution Med. Dent. Sci. 2016;5(78):5796-5798, DOI: 10.14260/jemds/2016/1308

\section{INTRODUCTION}

A case of Acute Encephalitis Syndrome (AES) is defined as a person of any age, at any time of year with the acute onset of fever not more than 5-7 days and a change in mental status (including symptoms such as confusion, disorientation, coma, or inability to talk) and/or new onset of seizures (excluding simple febrile seizures).(1) Japanese Encephalitis (JE) is presently a major cause of 'Acute Encephalitis Syndrome' (AES). Japanese encephalitis is a viral disease caused by an enveloped single stranded positive sense RNA virus of the genus Flavivirus family Flaviviridae.(2,3) It is a mosquito borne

Financial or Other, Competing Interest: None.

Submission 22-08-2016, Peer Review 15-09-2016,

Acceptance 21-09-2016, Published 28-09-2016.

Corresponding Author:

Debalina Das,

95 Santigarh, Graham Road,

Kolkata-700040,

West Bengal.

E-mail: drdebalinadas63885@gmail.com

DOI: $10.14260 /$ jemds/2016/1308 disease transmitted by Culicine mosquitoes, most notably by Culex tritaeniorhynchus \& Culex vishnui and occasionally caused by Culex gelidus, Culex fuscocephala, Culex annulus and Culex annulirostris. It is a zoonotic disease i.e. infecting mainly animals and incidentally man. It is transmitted mainly by pig to mosquito to pig cycle or Ardeid bird (herons, egrets) to mosquito to Ardeid bird cycle. Pigs are amplifiers of the virus. Birds are the reservoir of JE virus but are asymptomatic. ${ }^{(4)} \mathrm{JE}$ is reported from different parts of India.

The disease is endemic in 14 states with Assam, Bihar, Haryana, Uttar Pradesh, Karnataka and Tamil Nadu reporting outbreaks every year \& contributing about $80 \%$ of cases. (5) It has also been reported from West Bengal.(6) There is continued occurrence of sporadic cases and small outbreaks of JE in Bankura and Purulia districts of West Bengal. However, recent published data regarding the incidence of JE from this part of West Bengal is not available. Hence, our aim was to analyse the Japanese B encephalitis (JE) seropositive cases from various rural, urban and semiurban areas of these two districts of West Bengal. 


\section{MATERIALS AND METHODS}

The study was undertaken between January 2014 to December 2014 after obtaining ethical clearance from the institutional ethics committee. As isolation of JE virus from clinical specimens is difficult due to low level of viraemia and rapid development of neutralising antibodies against it, (7) the confirmation of a suspected case of JE requires the detection of JEV specific IgM by IgM capture ELISA in clinical samples. This assay distinguishes between JE and Dengue virus, which are serologically cross reactive. (8) CSF and serum samples were collected by lumbar puncture and venepuncture respectively from patients admitted with acute encephalitis syndrome from Paediatric and Medicine wards. All turned out to be unvaccinated. Uncentrifuged CSF and serum samples were analysed for JE specific IgM antibody by IgM antibody capture enzyme linked immunosorbent assay (MAC-ELISA) using kits from NIV (Pune). OD (Optical Density) value was taken by ELISA reader.

\section{RESULT}

During the study period, samples from 287 suspected patients were tested for JE out of which $29(10 \%)$ were positive for IgM antibodies. IgM positivity was $16(55 \%)$ in males and $13(45 \%)$ in females. Out of the 29 reactive cases, 13(45\%) were paediatric cases ( $<12$ years) and $16(55 \%)$ were adults.

\begin{tabular}{|c|c|c|}
\hline Age Distribution & Number & Percentage \\
\hline 0-12 years & 13 & $45 \%$ \\
\hline >12 years & 16 & $55 \%$ \\
\hline Table 1: Age Distribution of Patients Reactive for JE N=29 \\
\hline
\end{tabular}

The number of seropositive cases referred from Bankura and Purulia were $13(45 \%)$ and $16(55 \%)$ respectively. The percentage of IgM positive JE was found to be high during the months of September and October. Among 29 cases, 11 cases occurred in September (38\%) and 9 cases occurred in October (31\%).

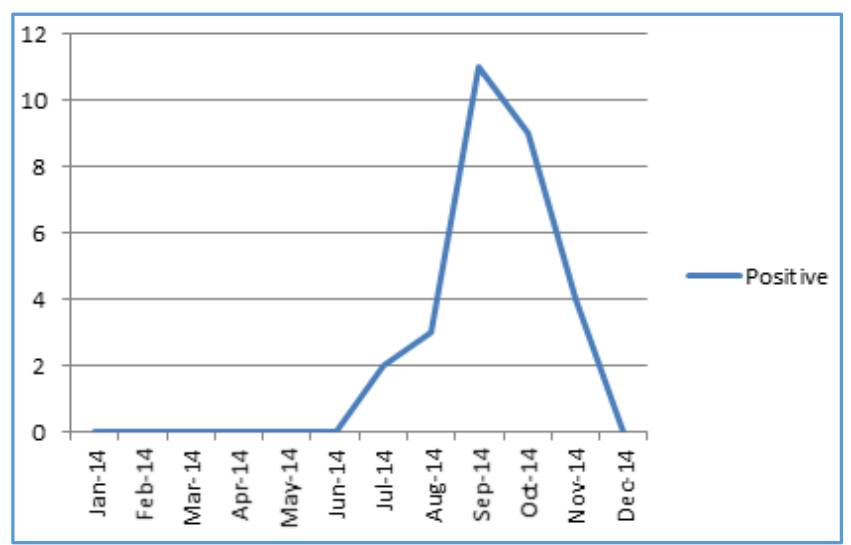

Fig. 1: Monthly Distribution of Cases

No death was reported in last year due to JE, but 8 (28\%) patients were discharged with sequelae.

\section{DISCUSSION AND CONCLUSION}

Among 287 patients, 29(10\%) were reactive for JE IgM MAC ELISA, which was corroborative with the findings of the study conducted by Bandyopadhyay et al at Virology laboratory at the Calcutta School of Tropical Medicine and Chakraborty et al at Swasthya Bhawan. $(9,10)$ IgM positivity was $16(55 \%)$ in males and $13(45 \%)$ in females. So there is no gender predilection which is similar to other studies. $(9,10)$

Of the 29 reactive cases, $13(45 \%)$ were paediatric cases ( $<12$ years) and $16(55 \%)$ were adults. The same trend was noticed by Chakraborty et al in West Bengal and Borthakur et al in Assam.(10,11) But in other studies, the number of seropositive JE was more in paediatric population than adult population. $(9,12)$ This change in trend was probably due to vaccination in 1-15 years age group. The Government of India has introduced JE vaccination with SA-14-14-2 vaccine in phased manner starting from 2006. According to IAP immunisation schedule, live attenuated cell culture derived SA 14-14-2 is given in a two dose schedule, first dose at 9 months of age along with measles \& second dose at 18 months of age along with DPT booster. Furthermore, all susceptible children up to 15 years of age are to be given 2 doses of the vaccine at 4 weeks interval during outbreaks or anticipated outbreaks. 132 districts have already been brought under JE vaccination as part of Universal Immunization Programme (UIP).(13)

The percentage of IgM positive JE was found to be high during the months of September and October. Bandyopadhyay et al have also reported higher incidence of JE during similar months. The continued occurrence of sporadic cases and small outbreaks during the monsoons is explained by the increased vector burden in the paddy field in this region of West Bengal. No death was reported in this period due to JE and 8 (28\%) patients were discharged with sequelae. Whereas other studies showed that approximately $20-30 \%$ of JE cases are fatal and $30-50 \%$ of survivors have significant neurologic sequelae.(14) In India, case fatality rate ranges from 10-70\%. However, with early detection and management of cases, it has come down to an average of approximately $20 \%$.(15)

\section{REFERENCES}

1. Ministry of health and family welfare. Guidelines for surveillance of acute encephalitis syndrome (with special reference to Japanese encephalitis). New Delhi 2006.

2. Vaughn DW, Barrett A, Solomon T. Flaviviruses (Yellow Fever, Dengue, Dengue Hemorrhagic Fever, Japanese Encephalitis, West Nile Encephalitis, St. Louis Encephalitis, Tick-Borne Encephalitis). In: Mandell GL, Bennett JE, Dolin $\mathrm{R}$, eds. Principles and practice of infectious disease. Vol 1. $7^{\text {th }}$ ed. Philadelphia: Elsevier, Churchill, Livingstone 2010:2133-56

3. Lindenbach BD, Thiel HJ, Rice CM. Flaviviridae: the viruses and their replication. In: Knipe DM (ed). $5^{\text {th }}$ ed. Fields virology. Philadelphia: Lippincott Williams \& Wilkins 2007:1101-52.

4. Gluber D, Kuno G, Flaviviruses ML. In: Knipe DM, Howley PM, Griffin DE, et al. (eds) 5th ed. Field's Virology. Philadelphia: Lippincott Williams \& Wilkins 2007; 34(1): 1185-90.

5. Ministry of health \& family welfare. Report of the working group on disease burden for the $12^{\text {th }}$ five year plan (20102011). Govt of India New Delhi 2011.

6. Ministry of health \& family welfare. Annual report to the people on health. Govt of India New Delhi 2012.

7. Scherer WF, Moyer JT, Izumi T. Immunologic studies of Japanese encephalitis virus in Japan. J Immunol 1959;83(6):582-93. 
8. Salomon T, Thao LTT, Dung NM, et al. Rapid diagnosis of Japanese encephalitis by using an immunoglobulin $\mathrm{M}$ dot enzyme immunoassay. J Clin Microbiol 1998;36(7): 2030-4.

9. Bandyopadhyay B, Bhattacharyya I, Adhikary S, et al. Incidence of Japanese encephalitis among acute encephalitis syndrome cases in West Bengal, India. Bio Med Research International Article ID 896749, 2013;2013:1-5.

10. Chakraborty D, Banerjee S, Maji D, etal. A descriptive study of Japanese encephalitis in West Bengal, India, based on surveillance data: changing pattern observed in recent years. Sch J App Med Sci 2015;3(1E):320-8.

11. Borthakur AK, Das N, Bora BJ. Data from the world health organization national network laboratory for Japanese encephalitis. J Glob Infect Dis 2013;5(2):76-9.
12. Kumaria R, Joshib PL. A review of Japanese encephalitis in Uttar Pradesh, India. WHO South-East Asia Journal of Public Health 2012;1(4):374-95.

13. Government of India Ministry of Health \& Family Welfare. National programme for prevention and control of Japanese encephalitis/ acute encephalitis syndrome. Delhi Directorate general of health services. National vector borne disease control programme 2014.

14. Campbell GL, Hills SL, Fischer M, et al. Estimated global incidence of Japanese encephalitis: a systematic review. Bull World Health Organ 2011;89(10):766-74.

15. World Health Organisation. Guidelines for prevention and control of Japanese encephalitis Delhi. Zoonosis division national institute of communicable diseases 2006. 